\title{
A pederastia se tornou política, Moor! ${ }^{1}$
}

Carta de Rafael Dias Toitio²

Resumo: O objetivo do texto foi dialogar com Marx sobre a análise marxista da diversidade sexual e de gênero, sobretudo para entender o atual momento histórico. Após uma rápida análise da história da relação entre marxismo e luta LGBT, a carta procura refletir sobre qual marxismo precisamos hoje, principalmente do ponto de vista da estratégia de este se constituir novamente como teoria hegemônica do conjunto das lutas sociais.

Palavras-chave: marxismo; capitalismo; diversidade sexual e de gênero.

\footnotetext{
${ }^{1}$ Este texto, em uma versão resumida e não na forma de carta, foi apresentado na sessão plenária Marxismo, gênero e sexualidade, quando participei como debatedor da Conferência de Cinzia Arruzza, no IX Colóquio Internacional Marx Engels (julho de 2018/Unicamp).
}

${ }^{2}$ Doutor em Ciências Sociais pela Unicamp e professor do ensino superior privado. 
Recife, 13 de agosto de 2018.

\section{Querido Marx,}

Já faz algum tempo que queria te escrever, mas me faltavam os meios para isso. Ou, pelo menos, um impulso que me tirasse da inércia, uma "onda" dissonante que me possibilitasse falar contigo sobre questões de uma sociedade que nunca comunicou tanto, mas faz isso valorizando uma diversidade absurdamente miserável de ideias e práticas políticas, onde o seu pensamento tem pouca possibilidade de ser compreendido. Além disso, eu confesso que até recentemente eu nutria uma paixão cega pelo marxismo, o que me impedia de falar com você de forma mais autônoma e que assim fosse merecedora de sua atenção.

São muitos e variados os temas e questionamentos que gostaria de tratar contigo, sobretudo a respeito da reflexão sobre o mundo atual e as formas de superar esse capitalismo neoliberal que pesa, de diferentes formas, sobre nossos ombros e cabeças. Mas, nesta carta, quero tratar de algo mais relacionado ao que tenho estudado e que é também, para mim, pessoal e politicamente fundamental. Trata-se do debate sobre a análise marxista da diversidade sexual e de gênero e sobre as relações de gênero e de sexualidade no atual momento histórico. Mais exatamente, a partir de uma rápida análise da história da relação entre marxismo e luta (hoje denominada) LGBT, gostaria de fazer alguns apontamentos para refletir sobre qual marxismo precisamos nos dias de hoje, sobretudo do ponto de vista da estratégia de se constituir novamente como teoria hegemônica do conjunto das lutas sociais.

De antemão, peço desculpas pela chateação de questionar sobre o que você ou Engels tenham escrito sobre o tema. Nós dois sabemos que cada um de vocês foi um "homem de seu tempo" e que suas análises, por mais brilhantes e inovadoras que fossem, apresentariam algum 
limite próprio do contexto histórico em que atuavam. Mesmo assim, para justamente pensar a questão dentro de uma perspectiva histórica, lembro-te de uma carta que você recebeu de Engels e por ele escrita em 22 de junho de 1869. Sim, também viraram livros e mercadoria as seleções de cartas trocadas entre vocês.

Mais exatamente, quero te lembrar sobre o comentário de Engels sobre o livro Uranismo, de Karl Heinrich Ulrichs, que você havia enviado para ele.

O Uranismo [Urnings] que você me enviou é algo muito curioso. Há revelações extremamente antinaturais. Os pederastas já são numerosos e estão descobrindo que constituem um poder no Estado. Só lhes falta a organização, mas, segundo parece, ela já existe em segredo. Além disso, contam com homens importantes em todos os partidos mais antigos e, até mesmo, nos mais recentes. E como eles têm homens tão importantes em todos os partidos antigos e até nos novos, de Rösing a Schweitzer, eles não podem deixar de triunfar. Daqui em diante, vai virar moda dizer guerre aux cons, paix aux trous-de-cul. Que sorte a nossa por sermos demasiados idosos. Assim, não temos a obrigação de pagar tributo com o nosso corpo diante da vitória desse partido. Mas e a jovem geração! Diga-se de passagem, apenas na Alemanha é que um tipo semelhante [Karl Ulrichs] pode manifestar-se e transformar tal obscenidade em teoria. Infelizmente, ele ainda não tem coragem de confessar publicamente o que é. Mas, está aguardando somente que o novo Código Penal da Alemanha do Norte reconheça os 'direitos da sacanagem' e a situação vai mudar completamente. Então, as coisas vão mal o suficiente para pessoas pobres como nós, com nossa tendência infantil para as mulheres $^{3}$ (MARX \& ENGELS, 2010, p. 295-6; tradução livre).

\footnotetext{
3 "The Urning you sent me is a very curious thing. These are extremely unnatural revelations. The paederasts are beginning to count themselves, and discover that they are a power in the state. Only organisation was lacking, but according to this source it apparently already exists in secret. And since they have such important men in all the old parties and even in the new ones, from Rösing to Schweitzer, they cannot fail to triumph. Guerre aux cons, paix aus trous-de culd will now be the slogan. It is a bit of luck that we, personally, are too old to have to fear that, when this party wins, we shall
} 
Não sei se você recorda, mas nessa época foram inventados termos como uranismo e homossexualidade para denominar a relação sexual entre pessoas de mesmo sexo. Apesar de ambos os termos terem ganhado certa popularidade, só o segundo se manteve vivo já nos fins do século XX. O termo hoje em desuso foi inventado por Ulrichs, o qual é considerado o primeiro militante homossexual, sendo também pioneiro na análise teórica e científica sobre a sexualidade, influenciando boa parte da sexologia que surgiria logo depois dele 4 .

Sabemos que o interesse de vocês no livro tinha a ver com o caso de Johann Baptist von Schweitzer e as disputas que vocês travaram com esse boy-lover ${ }^{5}$. Mas, acontece que as afirmações apaixonadas e ao mesmo tempo discriminatórias e preconceituosas de Engels e o teu silêncio sobre a questão fundamentaram, em grande medida, a visão de que o marxismo é um pensamento homofóbico e machista. Tudo bem, Marx, não precisa corar as bochechas, não há com o que se envergonhar! Sabemos que, naquele momento, faltavam-lhes elementos teórico-políticos suficientes para vocês afirmarem uma visão materialista e histórica da sexualidade. A perspectiva fortemente naturalizante expressa nas palavras de Engels - e por você quando colocava a família heterossexual como a forma mais natural de divisão

have to pay physical tribute to the victors. But the younger generation! Incidentally it is only in Germany that a fellow like this can possibly come forward, convert this smut into a theory, and offer the invitation: 'introite' etc. Unfortunately, he has not yet got up the courage to acknowledge publicly that he is 'that way', and must still operate coram publico 'from the front', if not 'going in from the front' as he once said by mistake. But just wait until the new North German Penal Code recognises the droits du culb; then he will operate quite differently. Then things will go badly enough for poor frontside people like us, with our childish penchant for females".

${ }^{4}$ Sobre a vida de Ulrichs, ver Kennedy (2005).

${ }^{5}$ Johann Baptist von Schweitzer foi uma importante liderança do movimento dos trabalhadores na Alemanha. Era seguidor de Ferdinand Lassalle e considerado o primeiro deputado social democrata declarado que foi eleito num parlamento europeu. Era politicamente desvalorizado por seus adversários que o classificavam como um amante de garotos [boy-lover]. Para uma leitura (crítica ao marxismo) sobre a relação de Schweitzer com Marx e Engels, ver Kennedy (1995). 
do trabalho ${ }^{6}$-, também estava presente na própria interpretação dada por Ulrichs que, na luta por direitos civis e contra as leis antissodomia, afirmava que as expressões da sexualidade eram simplesmente algo biológico e inato ao indivíduo. Seria preciso outros acontecimentos políticos e o acúmulo de mais formulações teóricas para a sexualidade e o gênero passassem a ser considerados de fato uma construção social. Muitas águas rolaram desde que você se foi, meu caro. A previsão de Engels, num certo sentido, se efetivou. Em muitos países, os "direitos da sacanagem" foram aos poucos conquistados. O berço do capitalismo, a Inglaterra, criminalizou os atos homossexuais até 1967. Na sua Alemanha, que estava dividida desde o fim da $2^{a}$. Guerra Mundial, a parte oriental descriminalizou tais atos em 1968, e a parte ocidental em 1969. Neste mesmo ano e exatamente um século depois dessa carta de Engels, estourou a Revolta de Stonewall, nos EUA, que foi o episódio que desencadeou o movimento de liberação gay e é considerado o início do moderno movimento LGBT. Ao mesmo tempo, a "obscenidade" não só se transformou em teoria; como também, ironicamente, a teorização sobre a "obscenidade" teve como uma das fontes principais de inspiração o próprio marxismo. Isso na medida em que, no surgimento da segunda onda do feminismo e do movimento de liberação homossexual, no final dos 1960, conceitos e perspectivas marxistas foram fundamentais para iniciar uma teorização da sexualidade e do gênero como relações de poder.

Contudo, foi ainda no século XIX que o marxismo, não a teoria mas a esquerda marxista, reconheceu a questão da sexualidade como uma questão política. Em 1898, August Bebel, como dirigente do Partido

\footnotetext{
${ }^{6}$ Um exemplo, em $O$ Capital: “Numa família e posteriormente numa tribo surge uma divisão natural de trabalho, em virtude das diferenças de sexo e de idade, numa divisão de base puramente fisiológica. Essa divisão amplia seus elementos com a expansão da comunidade, com o crescimento da população e notadamente com o conflito entre as diversas tribos e a subjugação de uma a outra". O próprio Engels acrescentou, na terceira edição da obra, uma nota informando que estudos posteriores demostraram que a família não se constituiu antes da tribo, mas sim ao contrário; a tribo como forma primitiva de associação humana foi que precedeu as formas de família (MARX, 2006, p. 406).
} 
Socialdemocrata Alemão, foi o primeiro político a proferir um discurso público em defesa da homossexualidade, durante a revisão do Código Penal. Bebel defendia a revogação da lei de antissodomia alemã, com base na petição elaborada pelo Comitê Científico Humanitário, considerada a primeira organização ativista homossexual do mundo (BEBEL, 1978).

No entanto, durante o século $X X$, enquanto a luta e as conquistas do movimento operário abriam caminho e inspiravam a formação de outras lutas e movimentos sociais, foi no mínimo controversa a relação da esquerda marxista com a questão da sexualidade. Na União Soviética pós-revolucionária, uma preocupação que se mostrou muito forte foi em torno da "libertação sexual". Dentro de uma série de discussões e ações em torno da família, do divórcio, do aborto, da condição da mulher e da sexualidade, o governo bolchevique, como lembrou Green (2003, p. 32), aboliu as leis contra os atos homossexuais já em outubro de 1917, junto com as legislações czaristas, e não voltou a criminalizála no primeiro Código Penal soviético, de 1922.

Mas, se a revolução socialista foi essencial para divulgar e aprofundar o debate político da questão da "libertação sexual", esse processo não sobreviveria ao período stalinista, quando a diversidade sexual e de gênero voltou a ser oficialmente proibida. No mesmo pacote estavam a abolição do direito ao aborto e a propaganda do regime em defesa da família tradicional. Para o stalinismo, a homossexualidade era uma degenerescência burguesa e, dentro da União Soviética, seria produto da decadência do segmento burguês da sociedade ${ }^{7}$.

Ironicamente, meu caro, a justificativa stalinista centrada nessa ideia de "degenerescência" era fundamentada da mesma maneira que a noção da ciência burguesa. Esta julgava como antinatural qualquer forma de sexualidade que não a forma dominante: isto é, heterossexual monogâmica e voltada para a reprodução. O que era visto fora disso era

${ }^{7}$ Para uma leitura crítica sobre a homossexualidade nos primeiros anos da Revolução Russa, que continuou alvo de perseguição mesmo diante a descriminalização, ver Jesus (2010).

182 A pederastia se tornou política, Moor! 
considerado uma doença, uma degeneração biológica. Para pensarmos como essa concepção ainda é forte, só em junho deste ano, quando comemoramos 200 anos de seu nascimento, que a transexualidade deixou de ser considerada doença mental pela Organização Mundial de Saúde.

Com o surgimento do movimento homossexual e da segunda "onda" do movimento feminista, novas interpretações se constituíram no campo do marxismo para explicar as questões que motivaram a formação desses movimentos. Ricas análises foram produzidas por este campo, sobretudo com a formação da corrente teórico-prática do feminismo marxista e com as discussões fundamentadas nas contribuições de Herbert Marcuse sobre a sexualidade no capitalismo. No entanto, formou-se uma leitura hegemônica dentro do marxismo que tendia a desvalorizar essas lutas. Alguns posicionamentos afirmavam tais movimentos como "contrarrevolucionários", "liberais" e "pequeno-burgueses", por se centrarem em questões consideradas individuais e individualistas. Já outra explicação, ainda muito viva atualmente, parte da ideia da existência de uma luta principal e outras secundárias; o que justificou a falta de interesse e a ausência de esforços para contribuir com o que era então secundário ${ }^{8}$.

Em relação à América Latina e o Brasil, o historiador James Green (2003, p. 34) apontou que, até a década de 1990, indivíduos ou correntes dentro de organizações libertárias, socialdemocratas e algumas formações trotskistas foram exceções em relação à profunda homofobia da esquerda latino-americana. E, ainda que não haja um levantamento completo da história da fundação dos primeiros grupos politizados de homossexuais na região, tudo parece indicar que a maioria dos grupos que surgiu entre o início dos anos 1970 e o dos 1980 teve, entre seus fundadores e lideranças, membros de partidos comunistas ou de seus grupos dissidentes, ou ainda, provenientes de outras formações da esquerda (GREEN, 2003, p. 25).

${ }^{8}$ Ver Green (2003); Toitio (2017). 
Ainda hoje no Brasil, parte significativa das lideranças do movimento LGBT atual iniciou suas trajetórias em movimentos ou partidos marxistas (ou com correntes marxistas). Desde o seu início, a construção do movimento LGBT sempre esteve colada com o fortalecimento das organizações e das lutas da esquerda. Mas, até bem pouco tempo, eram raros os partidos que pautavam a questão LGBT e só nos últimos anos que, na maioria dos partidos marxistas, a questão ganhou legitimidade para a formação de setoriais e coletivos LGBT, passando a tratar a pauta da diversidade sexual e de gênero como uma frente de luta. E não só partidos, mas também movimentos de juventude e movimentos como o MST, que em 2016 formou o Coletivo LGBT Sem Terra.

Esse processo, importante lembrar, foi precedido por outro: a chegada do movimento LGBT ao Estado pelo menos desde meados dos anos 1990. A pauta LGBT ganhou aos poucos reconhecimento político pelo governo federal e dentro do Congresso Nacional e do judiciário, adentrando em alguns setores da institucionalidade política. No mandato de Lula, que ainda está preso - você deve ter imaginado que o golpismo não vacilaria -, foi criado o primeiro programa de políticas públicas e, ao longo do tempo, a construção de espaços de participação, como conferências e conselhos. Mas, a esse processo se constituiu uma violenta ofensiva conservadora, organizada em torno da - pasme você! - "bancada evangélica". A existência dessa bancada no parlamento brasileiro é a prova mais viva da falácia que é a visão de que as sociedades e suas "democracias" estão em evolução.

De todo modo, essas disputas na "cena política" contribuiram para a pauta LGBT ganhar definidamente visibilidade no debate público. Sobretudo mais recentemente, após dois importantes episódios. A aprovação pelo STF da união civil entre pessoas do mesmo sexo, em 2011, momento que a reação conservadora se recrudesceu de forma mais consistente. E em 2013, quando as manifestações durante as Jornadas de Junho conseguiram barrar a tramitação do projeto de lei apelidado de "cura gay" na Câmara dos Deputados; projeto que 
havia sido proposto por uma das principais lideranças da "bancada evangélica". A partir dali, Marx, "saíram do armário" os partidos de esquerda que ainda se recusavam a se posicionar sobre o tema, sendo crescente o estreitamento dos laços entre esquerda partidária e movimento LGBT.

No mesmo período, na academia, surgiram alguns estudos interessados em analisar a questão da diversidade sexual e de gênero a partir do marxismo, ou pelo menos considerando as contribuições marxistas. Jovens pesquisadoras/es LGBT interessadas/os em análises e temas como a articulação entre exploração do trabalho e opressão; o modo de vida das/os trabalhadoras/es LGBT; a relação entre preconceito, violência e classe; a relação movimento, partido e Estado; a discussão teórica entre feminismo e marxismo9. Passamos a dedicar nossas monografias, dissertações e teses para isso. Mas, apesar de desenvolvermos nossos estudos na academia, eles se inspiraram antes na prática militante, haja vista que esses primeiros pesquisadores e pesquisadoras atuavam em diferentes partidos e movimentos marxistas (movimentos como o de juventude, feminista e claro LGBT). Com isso, passamos a impulsionar o voo da coruja de Minerva que sobrevoaria sobre o nosso crepúsculo.

E se hoje temos infinitamente mais perguntas do que respostas, estamos convencidos/as de que o caminho é articular à análise marxista as contribuições do feminismo e dos estudos de sexualidade e gênero. Mais especificamente, estas recentes pesquisas têm privilegiado o diálogo não apenas com o feminismo marxista, mas com duas vertentes teóricas que ganharam força no debate brasileiro: o feminismo materialista francês e o feminismo pós-estruturalista, que tem como referência o trabalho de Michel Foucault ${ }^{10}$.

\footnotetext{
9 Existem ou estão em andamento estudos e pesquisas de graduação, mestrado e doutorado. É possível citar alguns trabalhos já finalizados: ALVES (2016), EFREM FILHO (2017), CISNE \& SANTOS (2018), OLIVEIRA (2015), TOITIO (2016).

${ }^{10}$ Para uma análise que retoma o marxismo feminista, a partir do debate da reprodução social, e faz isso incluindo as contribuições da teoria queer, ver Arruzza (2011, 2018).
} 
Confesso que, além da vertente marxista, tenho me aproximado mais da pós-estruturalista, sobretudo pela capacidade desta de oferecer categorias que possibilitam uma análise materialista da sexualidade e do gênero. Por ora, estou convencido disso, ainda que alguns colegas marxistas afirmem que eu capitulei e "peleguei" diante dessa abertura teórica; ou mesmo que a relação entre marxismo e feminismo pós-estruturalista seja complicada e não tão direta, sendo um caminho de análise bastante tortuoso. Mas, por ter dado importantes contribuições para refletir sobre a diversidade sexual e de gênero no mundo atual, muitos de nós temos optado por esse caminho mais "tortuoso". E gostaria de elencar algumas rápidas razões porque acredito que certas categorias e perspectivas do pós-estruturalismo podem ser incorporadas criticamente pela teoria marxista, como já tive oportunidade de discutir (TOITIO, 2017).

Em primeiro lugar, porque trazem uma concepção radicalmente histórica e crítica da sexualidade e do gênero. Concepção que ganhou consistência teórica após a emergência dos movimentos que surgiram na efervescência política do final dos anos 1960. Em segundo lugar, como lembrou James Williams (2013, p. 39), mesmo que o pósestruturalismo tenha se constituído rompendo com o marxismo, ele se formou considerando e trabalhando com as suas contribuições, Marx. E fez isso utilizando perspectivas e desenvolvendo insights do próprio marxismo. De acordo com o nosso Nicos Poulantzas, Foucault confirmou muitas análises marxistas ou mesmo as enriqueceu em inúmeros pontos, o que ele evitava dizer, ao mesmo tempo em que oferecia uma análise materialista de certas instituições de poder (POULANTZAS, 1980, p. 75).

Além disso, o pós-estruturalismo é anticapitalista, pelo menos para seus primeiros teóricos. Se atualmente esse aspecto tende a ser ocultado pela leitura hegemônica do pós-estruturalismo nos estudos

E atualmente, está se consolidando uma corrente, nos EUA, intitulada queer Marxism, que abriga autores como Drucker (2014) e Floyd (2009). 
de gênero, isso não significa que não exista o viés anticapitalista nessa teoria. É interessante notar como Foucault, na História da sexualidade, se esforçou em demostrar o papel da sexualidade para o desenvolvimento do capitalismo industrial. Para Foucault, a sexualidade, como forma de disciplinarização e "assujeitamento" para a vida industrial e urbana, foi fundamental para "ajustar as populações aos processos econômicos", garantindo a inserção controlada dos corpos na produção. Junto a isso, o controle do crescimento populacional, nesse momento histórico, foi fundamental para a construção dos Estados imperialistas, o que passou a ser assegurado, entre outros elementos, pela proliferação de leis nacionais que criminalizavam a homossexualidade (e a diversidade como um todo). É interessante notar que o avanço do liberalismo que, como você evidenciou, só tem compromisso com a liberdade do capital - não representou um avanço na luta pela liberdade sexual. Pelo contrário, o Reino Unido voltou a criminalizar a homossexualidade masculina em 1885, dois anos depois que você morreu. Já o Império Alemão havia feito o mesmo quando foi fundado, em 1871.

Por último, destaco as contribuições de Judith Butler e, particularmente, seu conceito de "matriz heterossexual". Enquanto você, Marx, nos deu a lógica do capital, Butler evidenciou com esse conceito a lógica cultural que organiza as relações de gênero e de sexualidade em nossas sociedades ocidentais. A "matriz heterossexual" entendida como forma de tornar o mundo inteligível, de gerar identificações culturais e de se relacionar com as pessoas e com a sociedade. Para mim, essa perspectiva pode ser lida por lentes gramscianas: o heterossexismo como uma concepção de mundo que compreende a heterossexualidade como a forma natural e, por isso, deve ser compulsória. Essa concepção se tornou hegemônica historicamente e ainda está bastante arraigada no "senso comum" também no sentido dado por Gramsci.

Espero que não tenha te causado algum impacto saber dessa mudança no meu posicionamento teórico. Estranhamente com esse movimento, sinto-me mais próximo de você. E confesso que esse 
processo me levou a valorizar mais o diálogo entre as diferentes vertentes do próprio marxismo, procurando hoje me esquivar ao máximo de discussões que desvalorizam a riqueza das contribuições presente na diversidade do pensamento marxista. Não que devemos aceitar e concordar com tudo, mas sim procurar em cada vertente aquilo que ela pode ter avançado no entendimento da realidade.

Acredito que podemos fundamentar teoricamente nossas análises a partir de categorias e metodologia de uma vertente e, quando for demandado pela investigação, incorporar criticamente categorias de outras vertentes e de outras teorias. Isso no intuito de encontrarmos as categorias e formas de conceitualização que sejam politicamente produtivas e que sejam colocadas à prova da história e da análise materialista das práticas sociais; e não forçar a seleção delas dentro de um "cardápio" limitado por uma filiação teórica. Isso significa revelar e assumir a insuficiência de qualquer teoria para entender a complexidade das relações e processos que estudamos.

Se nesse caminho elementos do pós-estruturalismo podem ser incorporados pelo marxismo, isso não significa, contudo, que precisamos aderir ao projeto político-epistemológico pós-estruturalista, que tende a reduzir quase tudo à linguagem e ao discurso; que procura resumir a ação política às formas de resistência (fundamentais, mas insuficientes se mantidas no espontaneísmo); e que costuma negar qualquer tipo de normatividade e, com isso, qualquer tipo de projeto político. Além disso, não podemos esquecer que o pós-estruturalismo também deu a sua contribuição para a constituição de uma caricatura do marxismo, muito presente nos dias atuais, que o rotula como uma teoria arcaica, autoritária e normativa.

Os/as autores/as pós-estruturalistas não deveriam cuspir no prato que comeram. Como aponta Peter Drucker, por exemplo, se os movimentos queer prezam pela auto-organização, na luta contra os muitos mecanismos de normalização sexual, essa visão sobre a organização da luta social, no entanto, raras vezes é associada ao seu primeiro pensador político: você, Marx, que colocava a auto- 
organização e a auto-emancipação como elementos centrais de uma estratégia de libertação humana. Só que o autor lembrou que tragicamente, no curso do século XX, a tradição por você fundada foi identificada com movimentos e organizações que pouco ou nada tinham a ver com essa perspectiva (DRUCKER, 2014, p. 17).

De todo modo, hoje me preocupa menos as fraturas decorrentes dos embates teóricos e me importa mais como podemos aprofundar a reflexão de questões relacionadas à diversidade sexual e de gênero considerando as transformações recentes. Como essas questões se dão hoje, quando várias gerações de trabalhadores/as já se constituíram no capitalismo e interiorizaram suas práticas disciplinares como naturais? Quais as possibilidades e dilemas gerados pela formação de uma superpopulação no mundo? Qual o significado histórico dos avanços das tecnologias reprodutivas? Ou o da proliferação "silenciosa" de novas famílias e de práticas não heterossexuais (principalmente) nos países capitalistas ocidentais?

Hoje, do "movimento" de pederastas que você conheceu e do movimento homossexual que se constituiu ao longo do século $X X$, houve uma proliferação de identidades e movimentos que se colocam cada vez mais como diversidade: transexuais, travestis, lésbicas, bissexuais, intersexuais, gays, queer... cuja existência desafia o que nosso inconsciente e crenças concebem de mais natural. Ao mesmo tempo, novas famílias e modos de vida se difundiram. Casais homossexuais e transexuais que adotam ou mesmo que geram filhos/ as, e que contribuem para a reprodução social da vida. $\mathrm{O}$ que você conheceu, Marx, como masculino e feminino vem se descorporificando a cada dia do "corpo sexualizado", rompendo com os grilhões que historicamente vem oprimindo aquelas e aqueles que não conseguiram se adequar ao "regime" heterossexista.

Ao mesmo tempo, eu tendo a concordar com alguns autores, como Vladmir Safatle, que defende um deslocamento dos regimes disciplinares e de controle, que se organizam cada vez mais em torno do neoliberalismo. Este entendido não só como "modo de regulação" 
econômica, mas também como regime de gestão social e produção de formas de vida, que traz uma corporeidade que lhe é própria e constituída em torno da internalização de "um ideal empresarial de si" (SAFATLE, 2016, p. 137-8). A nossa vida gerida como uma empresa e organizada a partir da lógica custo-benefício é hoje um potente dispositivo disciplinar, que tem ganhado cada vez mais centralidade frente a outros mecanismos ideológicos de poder (SAFATLE, 2016).

Entretanto, mesmo diante dessas e de outras transformações, isso não significou que o heterossexismo perdeu sua efetividade. Ele sobreviveu às mudanças do capitalismo e continua sendo a sexualidade hegemônica. Reproduz-se como forma de inteligibilidade da realidade social que ainda organiza a produção de identidades, subjetividades e práticas, que pode voltar a ser legalmente obrigatória a depender de como serão tratados os problemas como quedas bruscas nas taxas de fecundidade ou o envelhecimento ou encolhimento da população de um país. Uma maior visibilidade e tolerância com o tema, não anula o fato de a diversidade sexual e de gênero continuar sendo o outro, o diferente, que pode ser aceito ou eliminado a depender do contexto e das correlações de força. Em três décadas, a Hungria diminuiu quase um milhão de habitantes, devido à emigração e à baixa natalidade. Isso fortaleceu a extrema direita que voltou a eleger o primeiro ministro e fez da defesa da família tradicional uma das principais bandeiras como informa Léotard \& Lepeltier-Kutasi (2018).

Devemos considerar que o neoliberalismo já deu uma resposta ao dilema da diversidade sexual e de gênero, que é tratada como nicho de mercado e como liberdade individual, desconsiderando o conjunto das condições necessárias à efetivação e ao exercício dessa liberdade. O marxismo precisa também se questionar se lhe interessa dar uma resposta também a essa questão. Defendo que sim, isso na medida em que uma teoria que pretende a transformação radical do modo de produção social, precisa também pensar sobre a reprodução social a ela ligada. Se a produção e reprodução social da vida determina a formação das nossas relações, práticas e formas de pensamento, 
devemos então voltar à formulação de Engels que inclui a reprodução biológica como um dos momentos fundamentais da reprodução social.

Essa questão foi e ainda é amplamente discutida pelo feminismo marxista e o pós-marxista que se constituiu a partir do final dos anos 1960. Reprodução biológica garantida, historicamente, pelo controle da sexualidade da mulher, pela divisão sexual do trabalho e pela heterossexualidade compulsória. $\mathrm{O}$ que conhecemos hoje como população LGBTI foi constituída por meio da violência gerada pela necessidade de manter esse modelo de reprodução material de corpos e de força de trabalho. Essa população, que não é definida no processo de produção social, sofre muito das consequências de um capitalismo não cego às hierarquias de gênero e de sexualidade. As poucas (e insuficientes) pesquisas recentes que foram feitas mostram a tendência, nos países capitalistas, de as pessoas LGBT ganharem menores salários que as pessoas heterossexuais; e de terem maior dificuldade de conseguir empregos melhores ou cargos de chefia ${ }^{11}$. Além da discriminação e do preconceito cotidianos no espaço de trabalho.

Vale destacar que aquelas pessoas que mais transgridem as normas e concepções de gênero são as que mais sofrem as consequências. Como no caso de gays afeminados ou lésbicas masculinizadas que são direcionadas muitas vezes a determinados empregos e cargos (e excluídos de tantos outros). Ou como é mais gritante no caso de travestis e transexuais que estão fortemente no trabalho informal e precário, como a prostituição (principalmente no caso das travestis e mulheres transexuais). Como expressam uma forma de ser não legitimada socialmente, travestis e transexuais, que tendem a se concentrar nas classes populares, encontram um severo limite ao acesso à educação, saúde, habitação, transporte e um longo etc.

\footnotetext{
${ }^{11}$ Ver por exemplo: OIT/CONFERÊNCIA INTERNACIONAL DO TRABALHO (100ª Sessão). Igualdade no trabalho: Um desafio contínuo, 2011. Disponível em: https:// www.ilo.org/public/portugue/region/eurpro/lisbon/pdf/relatorioglobal_2011.pdf. Acesso em set. 2018.
} 
O marxismo pode voltar a ser valorizado para análise de questões como essa, para evidenciar como a atual selvageria capitalista se alimenta da articulação da exploração de classe com complexas e arraigadas formas de opressão. Mas, a questão é como o marxismo vai compreender as lutas feminista e LGBT e se vai investir ou não em uma teorização que dê legitimidade às vivências e às formas de vida que, concretamente, constituem a diversidade sexual e de gênero. Se os movimentos ligados à reprodução social ganharam espaço no debate público, na política institucional e na constituição de militantes e organizações, isso não precisa ser lido como uma perda de espaço das lutas ligadas ao trabalho e à produção econômica. Até mesmo porque isso seria o fim do Estado conforme o conhecemos.

É claro que as demandas desses movimentos podem servir para diminuir a visibilidade das lutas de classe. No Brasil, pós-golpe os debates de sexualidade e de gênero são mobilizados cada vez mais para afirmar a existência de uma inexistente democracia. Nas atuais eleições, todos os candidatos se tornaram a favor da igualdade entre homens e mulheres e críticos ao machismo e à violência misógina. Nesse teatro, não há mais político machista. Até mesmo o governo golpista, que se constituiu tendo como um dos apoios principais o conservadorismo religioso organizado no legislativo, baixou uma norma que possibilita o uso do nome social de travestis e transexuais nas escolas do ensino básico. E o nome social também será respeitado nessas eleições, pela primeira vez. Uma cortesia do judiciário, em um momento em que ele é descaradamente um dos principais violadores da lei.

Sim, não é necessário me lembrar que nesse mesmo processo houve um absurdo retrocesso nas políticas e nos direitos das classes trabalhadoras. Mas, isso não significa que um conjunto de pautas (subalternas) foi anulado em nome de outro; e sim apenas que um pode ser instrumentalizado para diminuir a visibilidade de outro no jogo de disputas de projetos e demandas feitas no Estado. O que gostaria de te chamar a atenção é como vamos interpretar essas questões. Não podemos aceitar mais o discurso de muitas correntes marxistas que 
insistem em localizar a explicação do fracasso das lutas proletárias em eventuais conquistas e avanços de outras lutas subalternas. Fazem isso sob o risco de menosprezar ou diluir na análise o protagonismo de nossos inimigos, pois essa discussão raramente é relacionada com o jogo hegemônico do capital e a corporeificação silenciosa do neoliberalismo pelas classes trabalhadoras.

Nesse sentido, Marx, gostaria de concluir pontuando alguns elementos que acredito ser fundamental para o marxismo se constituir novamente como força de um novo processo de revolução social. De início, precisamos de uma teoria que entenda a totalidade das lutas sociais e, mais que isso, uma teoria que legitime essas lutas, ajudando a lançar luzes sobre seus dilemas e conflitos. Como não sabemos exatamente qual o conjunto de lutas e conflitos que pode ganhar a cena politica em uma determinada conjuntura, precisamos investir em um marxismo que não hierarquize a importância das lutas de antemão.

Cabe investir na reflexão sobre as diversas "dimensões" da vida social e não debater apenas aqueles temas consagrados pela teoria. É preciso investir na produção de um marxismo vivo, que se desenvolva com a história e que aprenda reiteradamente com ela. Um marxismo que considere as lutas em sua diversidade e em sua complexidade. Um marxismo que continue analisando como fazemos a história sob determinadas condições, mas que compreenda, como afirmou Stuart Hall (2013), que as condições determinadas não são mais somente aquelas relacionadas diretamente à produção econômica e às classes sociais.

Além disso, é importante olhar para a realidade social menos como uma realidade dividida em instâncias e esferas. E mais, como uma realidade conformada por relações sociais hierárquicas entre grupos ou classes sociais (no caso das relações de produção). Relações de classe, raça, gênero e sexualidade, não como três ou quatro sistemas político-econômicos. Mas, como relações sociais que são constituídas nas disputas e embates em torno da construção de formas hegemônicas: lutas entre modos de produzir e reproduzir a vida, mas também lutas 
entre formas de ser, sentir e conceber a realidade, lutas entre formas de constituir e controlar corpos, desejos e subjetividades. Relações articuladas concretamente e que ativam processos econômicos, políticos e culturais, que provocam mudanças e continuidades.

Penso, inclusive, que o marxismo deve saber dialogar ou mesmo assimilar os desafios teóricos e epistemológicos colocados pelo feminismo; e que assimile aquilo que o feminismo tem de mais combativo e radical. Defendo um marxismo que assimile das lutas sociais aquilo o que elas têm de mais produtivo: tanto do ponto de vista da capacidade de compreensão de nossa realidade, quanto da possibilidade de organização das classes e os grupos subalternos.

Mais do que nunca, é necessário lembrar a sua afirmação, nas teses críticas sobre Feuerbach, de 1845, que não importa apenas interpretarmos o mundo sim transformá-lo(MARX, 2007, p. 535). Entre outras coisas, isso nos responsabiliza a buscar uma reflexão permanente sobre o que significa e qual a amplitude dessa transformação; e sobre quais as questões que serão interpretadas pelas lentes da liberdade e da igualdade. Nesse desesperador começo do século XXI, acredito que o desafio do marxismo é evidenciar a permanência da necessidade de uma revolução socialista, mas pensando a transformação justamente a partir da perspectiva da totalidade das relações sociais, em especial aquelas hierarquicamente estruturantes, no intuito de potencializar as disputas pela organização material e simbólica da produção e reprodução social em torno de uma nova hegemonia.

Apesar das dificuldades e inseguranças da conjuntura, o atual momento de crise no Brasil tem sido um solo fértil para pensar essas questões. Ao mesmo tempo, o interesse no estudo marxista das forças políticas ganhou nova notoriedade, pois não se pode explicar o Golpe de 2016 sem uma análise da dinâmica das lutas de classe. A ilusão de que o neoliberalismo pode garantir liberdade e maior igualdade entre as classes tem se desvanecido. E, com isso, teus escritos voltam a fazer sentido para mais e mais pessoas. Somos eternamente gratos pela revolução teórica que você protagonizou e que provocou movimentos 
e irrupções políticas em todo o mundo. Por isso, gostaria de terminar lhe dedicando alguns versos de Álvaro de Campos, heterônimo de um poeta português que você não conheceu. Hesitei em transcrevê-lo devido à certeza de que seria piegas, mas não posso me furtar de lhe render essa singela homenagem.

Mestre, meu mestre querido!

Coração do meu corpo intelectual e inteiro!

Vida da origem da minha inspiração!

Mestre, que é feito de ti nesta forma de vida?

Seja lá o que for, mestre, teu espectro continua a rondar entre nós. Ele está vivo e ganha fôlego renovado nos processos traumáticos que constituem os países periféricos, onde a incapacidade do capitalismo de solucionar as enormes e constantes desigualdades está escancarada, mesmo que profundamente naturalizada. Teu fantasma ainda assusta o capital já que as lutas e as condições precarizadas de trabalho e de vida, persistentes, voltam a tornar mais visível a conexão entre trabalho e mudança social e a desconexão entre vida vivida e vida desejada. E na medida em que seu pensamento insiste em contribuir na compreensão dessa complexa realidade, tuas ideias e ideais se recolocam como fontes de nossa inspiração.

Com carinho,

Rafael. 


\section{Referências bibliográficas}

ALVES, D. S. Movimento LGBT, Participação Política e Hegemonia. Porto Alegre, 2016. Tese (Doutorado em Ciência Política). Instituto de Filosofia e Ciências Humanas, Universidade Federal do Rio Grande do Sul.

ARRUZZA, C. Rumo a uma "União queer" de marxismo e feminismo? Lutas Sociais, São Paulo, n. 27, p. 159-171, 2. sem. 2011.

- Social Reproduction and Class Struggle (Mimeo). Texto apresentado na Conferência Marxismo, gênero e sexualidade. IX Colóquio Internacional Marx Engels, Campinas, Unicamp, julho de 2018.

BEBEL, A. The Man Who Spoke Out: 80th Anniversary of a Landmark in Gay Rights. Gay News, London, ed. 136, 1978 (On Homosexuality and the Penal Code - Online Version: Marxist Internet Archive. Disponível em: https://www.marxists.org/ archive/bebel/1898/01/13.htm. Acesso em ago. 2018).

CISNE, M.; SANTOS, S. M. Feminismo, Diversidade Sexual e Serviço Social. São Paulo: Cortez, 2018.

DRUCKER, P. Warped: Gay Normality and Queer Anticapitalism. Leiden/ Boston: Brill, 2014.

EFREM FILHO, R. Mata-mata: reciprocidades constitutivas entre classe, gênero, sexualidade e território. Campinas, 2017. Tese (Doutorado em Ciências Sociais). Instituto de Filosofia e Ciências Humanas, Unicamp. 
FLOYD, K. The Reification of Desire: Toward a Queer Marxism. Minneapolis: University of Minnesota Press, 2009.

GREEN, J. N. A luta pela igualdade: desejos, homossexualidade e a esquerda na América Latina. Cadernos AEL: homossexualidade, sociedade, movimento e lutas, Campinas, v. 10, n. 18/19, p. 13-41, 2003.

JESUS, D. S. Espiões e bárbaros entre camaradas: o amor que não ousava dizer o nome na União Soviética. Lutas Sociais, São Paulo, n. 24, p. 18-30, 1o sem. 2010.

KENNEDY, H. “Johann Baptist von Schweitzer: The Queer Marx Loved to Hate". In: HEKMA, G., OOSTERHUIS, H., STEAKLEY, J. (orgs.). In: Gay Men and the Sexual History os the Political Left. New York: Harrington Park Press, 1995.

. “Ulrichs, Karl Heinrich”. In: ALDRICH, R.; WOTHERSPOON, G. (orgs.). Who's who in gay and lesbian history. London, New York: Routledge, Taylor \& Francis e-Library, 2005.

LÉOTARD, C.; LEPELTIER-KUTASI, L. O medo de desaparecer. Le Monde Diplomatique Brasil, ano 11, n. 131, p. 18-19, jun. 2018.

MARX, K. O Capital: crítica da economia política (Livro I). 24 ed. Rio de Janeiro: Civilização Brasileira, 2006.

. "Ad Feuerbach (1845)". In: MARX, K.; ENGELS, F. A ideologia alemã. São Paulo: Boitempo, 2007.

MARX, K.; ENGELS, F. Collected Works. Letters 1868-70. S./1.: Lawrence \& Wishart, Electric Book, 2010 (vol. 43). 
OLIVEIRA, M. Diversidade Sexual e Mundo do Trabalho: uma análise a partir da experiência de trabalhadores gays e lésbicas do setor de telefonia/telecomunicações do Rio de Janeiro. 2015. Dissertação (Mestrado em Ciências Sociais). Instituto de Ciências Humanas e Sociais, Universidade Federal Rural do Rio de Janeiro.

POULANTZAS, N. O Estado, o Poder, o Socialismo. Rio de Janeiro: Graal, 1980.

STUART, H. Da diáspora: identidades e mediações culturais. 2. ed. Belo Horizonte: UFMG, 2013.

TOITIO, R. D. Cores e contradições: a luta pela diversidade sexual e de gênero sob o neoliberalismo brasileiro. Campinas, 2016. Tese (Doutorado em Ciências Sociais). Instituto de Filosofia e Ciências Humanas, Unicamp.

. Um marxismo transviado. Cadernos Cemarx, Campinas, n. 10, p. 61-82, 2017.

WILLIAMS, J. Pós-estruturalismo. 2. ed. Petrópolis, RJ: Vozes, 2013. 